Boise State University

ScholarWorks

Organizational Performance and Workplace

Learning Faculty Publications and

Presentations

Department of Organizational Performance and Workplace Learning

2020

\title{
Effects of Family-Supportive Supervisor Behaviors and Organizational Climate on Employees
}

Soo Jeoung Han

Boise State University

Gary N. McLean

Assumption University

This is an author-produced, peer-reviewed version of this article. The final, definitive version of this document can be found online at European Journal of Training and Development, published by Emerald Group Publishing, Ltd. Copyright restrictions may apply. doi: 10.1108/EJTD-12-2019-0195 


\section{Effects of Family-Supportive Supervisor Behaviors and Organizational Climate on Employees}

\author{
Soo Jeoung Han \\ Department of Organizational Performance and \\ Workplace Learning \\ Boise State University \\ Boise, Idaho, USA
}

\author{
Gary N. McLean \\ Graduate School of Management MBA and PhDOD \\ Programs \\ Assumption University \\ Bangkok, Thailand
}

\section{Purpose}

Abstract

The purpose of this study was to investigate the effects of family-supportive supervisor behaviors and organizational climate on employees' work-family conflict, job satisfaction, and turnover intentions.

\section{Design/Methodology/Approach}

To examine the causal relationship, the longitudinal panel data of the Work, Family, and Health Study were used, using the data of 664 respondents who participated in surveys from all four time-points at two Fortune 500 information technology (IT) companies.

\section{Findings}

The results of the data analysis suggested that family-supportive supervisor behaviors have a minimal, but statistically significant, impact on work-to-family conflict and organizational work-family climate. In addition, work-to-family conflict minimally mediated the relationship between family-supportive supervisor behaviors and employees' turnover intentions. An organizational work-family climate also had a small, but statistically significant, mediating effect between family-supportive supervisor behaviors and job satisfaction/turnover intentions.

\section{Practical Implications}

Our study has practical implications by noting that relying on only individual managers' roles or training managers to be family-supportive may not be enough to improve family-oriented organizational culture, work-life balance, and job-related outcomes.

\section{Originality/Value}

Using a longitudinal mediation model, we examined the effects of family-supportive supervisor behaviors and how those behaviors impact other variables over time. In spite of the expectation of such an impact, however, we found minimal effects among variables. This study is valuable as it can stimulate future research to advance the theoretical and practical understanding of family-supportive supervisor behaviors to help determine why we found that it had so little impact on both work-family conflict and a family-friendly organizational climate to increase employees' satisfaction to continue to work.

Keywords: work-family conflict, family-supportive supervisor behaviors, organizational climate, turnover intentions, job satisfaction

An increasing number of dual-earner partners, undefined gender roles, and longer working hours have highlighted the necessity of studying work-family conflict (Greenhausand et al., 2012; Valcour, 2007). Work-family conflict has been examined over the past 40 years and even more so within Human Resource Development (HRD) in the last 10 years to support employees better, develop organizations, and make policies and interventions around them (Munn, 2013). In the United States, on average, full-time employees devote 14.5 hours, $60 \%$ of their day, to personal care (e.g., 
eating, sleeping) and leisure (e.g., socializing with friends and family, hobbies, watching television, playing video games), just under the Organization for Economic Co-operation and Development's (OECD) global average of 15 hours (OECD, 2014). Denpending on the industry, the avarage employee's working hours vary in the U.S. In this study, we used an existing data base based on a survey of information technology (IT) employees in the U.S. as it is the largest computer-related industry. The IT industry changes quickly in terms of technology and that puts additional pressure on employees to work extended hours (Way, 2015). Many IT employees are struggling with work-family balance as they work nights and weekends in addition to traditional hours (Kaminski and Reilly, 2004).

Due to these challenges, many HRD scholars and practitioners are seeking ways to improve work-family balance by creating a supportive work-family environment (Fiksenbaum, 2014) to increase the hours spent for personal care and leisure. However, a supportive work-family environment cannot be built overnight. Although early work-family studies focused on how employees use formal workplace support, such as work-family policies, the field has recently shifted its research to address leadership, in particular, the informal role and development of family-supportive supervisor behaviors (Hammer et al. 2011; Major et al. 2008). To help employees manage work and family responsibilities, the role of family-supportive supervisors has been shown to enable employees' work-family balance, enhance their job satisfaction (Hammer et al., 2019; Hammer et al., 2011; Kossek et al., 2011) and work engagement (Rofcanin et al., 2017; Qing and Zhou, 2017), reduce turnover intentions, improve physical health (Hammer et al., 2011), and even improve sleep quantity and quality (Crain et al., 2014). Based on the literature, identifying the role of family-supportive supervisor behaviors to other job-related outcomes, such as job satisfaction, job performance, and turnover intentions (Hammer et al., 2013; Odle-Dusseau et al., 2012), is important.

\section{Problem Statement}

Does family-supportive supervision imapct turnover intentions or job satisfaction? Several studies have examined the positive relationship between family-supportive supervision and work-family conflict (WFC) (Greenhaus et al., 2012; Kossek et al., 2011). WFC refers to "a form of interrole conflict in which the role pressures from the work and family domains are mutually incompatible in some respect” (Greenhaus and Beutell, 1985, p. 77). However, scholars have been limited in their scope in capturing the complicated picture of how perceptions of work-family supervision impact individual level WFC and organizational level factors, like organizational climate and job-related outcomes. Therefore, in this study, we identified the effects of family-supportive supervisor behaviors on WFC and organizational climate, both of which may lead to job satisfaction and reduce turnover intentions.

In addition, encouraging individual's work-life balance, family-friendly policies, and family-supportive supervisors may not be enough without a work climate that supports those efforts (O’Neil et al., 2008). For example, IT employees face work-family conflicts due to the prevalence of excessive projects, stringent deadlines, and responsibilities after the normal nine-to-five workday, which results in high rates of turnover as compared to other industries (Borges, 2013). Job stress of IT employees was a main factor that reduced job satisfaction and increased turnover intention; an quality of work life also had a negative and significant relationship with turnover intentions (Hassan, 2014). However, research on organizational factors that reduce work-family conflict is somewhat limited. Typically, scholars have investigated individual level factors (e.g., family-supportive supervisor, work-family conflict, job satisfaction, turnover intentions) when dealing with work-life balance issues (Greenhaus et al., 2012; Hammer et al., 2011). More research would be useful if it adds organizational level factors, such as organizational climate (Allen, 2001; Kossek et al., 2011). As an example of organizational level factors, an organizational work-family climate refers to a supportive organizational culture where it supports employees' family needs, obligations, and personal situations, and promotes flexibility and tolerance (Allen, 2001).

Therefore, the purpose of this study is to examine the impact of family-supportive supervisor behaviors on employees' work-family conflict, organizational work-family climate, job satisfaction, and turnover intentions over time. This research can be beneficial for HRD practitioners (e.g., Ptt-Catsouphes et al., 2007) or HR managers by highlighting the importance of supervisors' roles in reducing work-family conflict and sharing family-supportive organizational climate. This research can be a starting point to think about how to increase employees' quality of work life and job satisfication and decrease subsequent turnover intention. This will be discussed more extensitvely in the concluding section. 


\section{Literature Review and Hypotheses Development}

Understanding the background identified in the literature on family-supportive supervisor behaviors and work-family conflict serves as a useful lens to investigate employees' experiences in organizations. Aligned with our purpose, we examined the relationships among the following constructs: (a) family-supportive supervisor behaviors, (b) organizational work-family climate, (c) work-family conflict, and (d) employees job-related outcomes, specifically job satisfaction and turnover intentions. We included hypotheses at the end of each section.

\section{Family-Supportive Supervisor Behaviors}

To examine family-supportive supervision, the concept of family-supportive supervisor behaviors (FSSBs) was used in this study. FSSBs are defined as supervisors' behaviors that support employees' family roles (Hammar et al., 2009). This concept has a critical link with two levels—individual and organizational—in terms of work-family support. According to Beauregard and Henry (2009), the individual level relates to employees' work-family conflicts, and the organizational level relates to an organizational work-family climate.

The role of work-family supervisor support in the workplace and in organizational literature has been identified as a critical component in reducing work-family conflict and improving well-being (Hammer et al., 2009; Kossek et al., 2011). Work and family social support are most related to WFC (Anderson et al., 2002; Michel et al., 2010). The combined effects of WFC and FSSBs were found to be significantly related to sleep quantity and quality (Crain et al., 2014).

In terms of theory, social exchange theory is often used in work-family studies to explain employees' positive and beneficial behaviors to an organization when the organization treated them favorably (Beauregard and Henry, 2009). Drawing on social exchange theory, which values relationships among individuals based on mutual trust and commitment, Bagger and $\mathrm{Li}$ (2014) found that the model linking FSSBs to job outcome variables through social exchange relationships was moderated by the level of organizational family-friendly benefits. Meta-analytic literature reviews also have shown that work-family supportive supervision tends to be strongly linked to WFC, and that supervisor support is the pathway through which employees develop organizational support perceptions (Kossek et al., 2011). Based on social exchange theory, leader-member exchange (LMX) perspectives have grown because a high-quality exchange between supervisors and their subordinates can impact work and family life (Tummers and Bronkhorst, 2014)

In addition, LMX perspectives can explain the supervisor-employee relationship, which has a strong association with an organizational climate and culture (Major et al., 2008). Typically, family-supportive supervisors encourage employees to have greater work schedule flexibility and use formal work-family policies (Poelmans and Beham, 2008) that can reduce WFC and create a positive organizational climate (Hammer et al., 2009). Previous researchers demonstrated the positive effects of FSSB on employees' work-family balance and their job satisfaction (Hammer $e t$ al., 2009; Hammer et al., 2011; Kossek et al., 2011) and lower turnover intentions (Hammer et al., 2011). Our research hypotheses were:

H1: Family-supportive supervisor behaviors have effects on work-family conflict.

H2: Family-supportive supervisor behaviors have effects on an organizational work-family climate.

H3: Family-supportive supervisor behaviors have effects on employees' job satisfaction.

H4: Family-supportive supervisor behaviors have effects on employees’ turnover intentions.

\section{Work-Family Conflict}

Over the past several decades, work-family conflict has been studied at organizational and individual levels uner worklife balance studies (Özbilgin et al., 2011). Work-life balance is defined as the extent to which individuals manage their work, family, leisure, and community responsibilities (Chandra, 2012; Munn, 2013). Women employees, for instance, have difficulty in meeting expectations about mothering when managing work and family life (Groysberg 
This is an author-produced, peer-reviewed version of this article. The final, definitive version of this document can be found online at European Journal of Training and Development, published by Emerald Group Publishing, Ltd. Copyright restrictions may apply. doi: 10.1108/EJTD12-2019-0195

and Abrahams, 2014). In work-life balance studies, concepts of work-family conflict (WFC) and family-work conflict (FWC) are commonly used (Netemeyer et al., 1996). WFC occurs when work interferes with family life, while FWC occurs when family interferes with work life (Frone et at., 1992; O’Brien et al., 2014).

Role theory suggests that role conflict between work and family tends to occur because managing both roles with limited resources (e.g., time, energy) is challenging (Bolino and Turnley, 2005). For example, the stress from employee roles may result in negative experiences with spousal or parental roles. We used WFC in our model and did not use FWC because the focus of our study was the job and how it interferes with family responsibilities. The previous studies showed that FWC partially mediated the relationship between family-supportive supervisors and work-family balance, whereas WFC fully mediated the relationship (Greenhaus et al., 2011). In addition, having a high WFC can reduce employee job satisfaction and performance (Beauregard and Henry, 2009; Fiksenbaum, 2014), which can lead to high turnover intentions (Anderson et al., 2002). We hypothesized:

H5: Work-family conflict has effects on job satisfaction.

H6: Work-family conflict has effects on turnover intentions.

\section{Organizational Work-Family Climate}

An organizational work-family climate is an important element in increasing employees' positive job-related outcomes. However, long work hours and intolerant organizational cultures and environments are negatively related to work-life balance (Valcour, 2007), which leads to low job satisfaction and high turnover intentions (O'Neill et al., 2009). When organizational climate implicitly pressures employees to dedicate more time to work but does not support work-family initiatives, employees are likely to experience WFC. Several studies noted that those who experience WFC tend to damage their physical and psychological health (Allen et al., 2000; Mesmer-Magnus and Viswesvaran, 2005) and have negative effects on their job-related outcomes, such as employee absenteeism and turnover intentions (Anderson et al., 2002).

In contrast, studies have shown that a positive work-family climate in organizations (Kossek et al., 2001) is critical for employee well-being and performance over time. For example, organizational family-friendly resources and the use of organizational family interventions (e.g., flexible working hours and job sharing) directly predicted reduced levels of WFC and increased job satisfaction (Brough et al., 2005). A positive organizational work-family environment can help employees balance competing demands from their work and home, which, in turn, can reduce WFC and enhance their job engagement and performance (Beauregard and Henry, 2009; Fiksenbaum, 2014). We hypothesized:

H7: An organizational work-family climate has effects on job satisfaction.

H8: An organizational work-family climate has effects on turnover intentions.

\section{Mediating Effects of Organizational Work-Family Climate and Work-Family Conflict}

We also investigated the mediating effects of WFC and organizational work-family climate between FSSBs and jobrelated outcomes. Despite the potential positive effects of such FSSBs, depending on individaul situations of work and family relationships or perceptions of organizational climte, FSSBs may work differently on employees' job satisfication and intention to quit the job. For example, as social exchange theory and leader-member exchange (LMX) perspectives indicate, employees are hesitant to use family-supportive benefits when managers do not encourage employees to utilize those benefits (Kossek et al., 2011). Qing and Zhou (2017) found that WFC mediated the relationship between FSSB and work engagement over time. In addition, Allen (2001) found that family-supportive work environments mediated the relationship between available family-friendly benefits and WFC, affective commitment, and job satisfaction. A family-supportive work environment mediated the relationship between supervisors' support and WFC (Allen, 2001; Kossek et al., 2011). We hypothesized:

H9: Work-family conflict mediates the relationship between perceptions of family-supportive supervisor behaviors and job satisfaction.

H10: Work-family conflict mediates the relationship between perceptions of family-supportive supervisor behaviors and turnover intentions. 
This is an author-produced, peer-reviewed version of this article. The final, definitive version of this document can be found online at European Journal of Training and Development, published by Emerald Group Publishing, Ltd. Copyright restrictions may apply. doi: 10.1108/EJTD12-2019-0195

H11: An organizational work-family climate mediates the relationship between perceptions of family-supportive supervisor behaviors and job satisfaction.

H12: An organizational work-family climate mediates the relationship between perceptions of family-supportive supervisor behaviors and turnover intentions.

\section{Methodology and Methods}

In this section, we describe our target population and sample for this study based on an archived survey, along with the measures used, their reliabilities and validities, and the data analyses used to test our hypotheses.

\section{Population and Sample}

Because of available data, we set our target population as Fortune 500 IT companies, utilizing the Work, Family, and Health Study (WFHS) collected by the Work, Family, and Health Network (WFHN) from 2009 to 2012. The WFHN is an interdisciplinary research project team at Harvard University. In order to access the restricted-use data, we submitted our IRB approval and research proposal to WFHN and received permission. The WFHN surveyed and interviewed all 823 employees from 26 technology industry work locations within two Fortune 500 companies in 2009. Of these, 717 employees (87.1\%) responded to the second survey after six months, $701(85.2 \%)$ to the third survey after 12 months, and $652(79.2 \%)$ to the fourth survey after 18 months. The demographics of the employees are shown in Table 1.

[Place Table 1 about here]

\section{$\underline{\text { Measures }}$}

Reliability and validity of the study measure are described below. The measures used, all of which were developed previously, are described here, along with the reliabilities and validities from the original studies, and, in a separate section, those in our study.

Reliability and Validity of Measures in Current Study. To test the validity of the measurement instrument, we conducted a confirmatory factor analysis (CFA); reliability was determined using Cronbach's alpha. The results of the CFA and Cronbach's $\alpha$ indicate that the measurement instrument met the criteria (factor loadings > .50; Cronbach's $\alpha>$.70) for validity (i.e., FSSB .79; WFC .89, OWFC .75; JS .71; TI .89) and the reliability (i.e., FSSB $\alpha=.88$; OWFC $\alpha=.82$; WFC $\alpha=.91$, JS $\alpha=.87$; TI $\alpha=.88$ ). As TI consists of only two items, an exploratory factor analysis using principal axis factoring approach and direct oblimin rotation was used, and the rest were analyzed using the CFA model of structural equation modeling.

We used a longitudinal model with four different time points to examine the effects of FSSBs over a period of 18 months. Each construct was measured at a different time point to see how FSSBs (first phase survey) influence WFC (second phase survey), OWFC (third phase survey), and JS/TI (final phase survey) over time and to see longer term impact. Each measurement is described below.

Family-Supportive Supervisor Behaviors (FSSBs). FSSBs were measured using the FSSB Short Form (FSSB-SF) developed by Hammer et al. (2009). FSSB-SF has four items, answered using a Likert-type scale of 1-5 for "strongly disagree" (1) to "strongly agree" (5). An example is, "Your supervisor makes you feel comfortable talking to him/her about my conflicts between work and non-work." In the original study, the validity was determined by confirmatory factor analysis (CFA) and the overall reliability was determined through Cronbach's alpha to be .82. To run the longitudunal anaylsis, the first phase survey data were used for FSSBs.

Work-Family Conflict (WFC). WFC was measured with the Work-Family Conflict Scale (WFCS) developed by Netemeyer et al. (1996). The five items had a scale from 1-5 for "strongly disagree" (1) to "strongly agree" (5). A sample item is: "The demands of your work interfere with your family or personal time." The reliabilities in the original study, using two samples, were determined to be .88 and .89 based on two samples. The validity was determined by CFA. To run the longitudunal anaylsis, the second phase survey data were used for WFC. 
This is an author-produced, peer-reviewed version of this article. The final, definitive version of this document can be found online at European Journal of Training and Development, published by Emerald Group Publishing, Ltd. Copyright restrictions may apply. doi: 10.1108/EJTD12-2019-0195

Organizational Work-Family Climate (OWFC). OWFC was measured using the Work Climate for Making Family Sacrifices Scale developed by Kossek et al. (2001). This scale consists of three items, also measured using Likerttype scales from 1-5 for "strongly agree" (1) to "strongly disagree" (5). An example item is, "In your workplace, employees are expected to take time away from their family or personal lives to get their work done.” The reliabilities in the original study were .74 and .84 based on two samples. The validity was determined by CFA. To run the longitudunal anaylsis, the third phase survey data were used for OWFC.

Job Satisfaction (JS). JS was developed by Cammann et al. (1983). The measure consists of three items using a Likert-type scale ranging from 1-5, using the same scales as before. An example item is, "In general, you like working at your job.” The reliabities, from two samples, were determined to be .77 and .87 based on two samples. The validity was determined by factor analysis, though the type was not specified in the article. To run the longitudunal anaylsis, the final phase survey data were used for JS.

Turnover Intentions (TI). TI was measured by Boroff and Lewin's (1997) two items using the same scales as before: "You are seriously considering quitting your company for another employer" and "During the next 12 months, you will probably look for a new job outside your company." The reliability was determined to be .70. No information about validity was provided by the original authors. To run the longitudunal anaylsis, the final phase survey data were used for TI.

The demographic variables (e.g., gender and marital status) were not used in the analysis as no evidence in the literature was found to make differences in our hypothesized model.

\section{Data Analyses}

The data were analyzed using: 1) descriptive statistics and Pearson zero-order correlations and 2) structural equation model analysis. The Mplus software program was used for testing the structural equation model. As the research model is a mediation model, we compared the two nested models, including the indirect mediation model (research model) and the direct mediation model (alternative model). To identify a better model, we performed the chi-square difference test. As fit indices for each model, we adopted the root mean square error of approximation (RMSEA), the TuckerLewis index (TLI), and the comparative fit index (CFI), as well as a $\chi^{2}$ statistic in order to consider parsimony of the model, receiving less influence from the sample size (Browne and Cudeck, 1993). Generally, the values of TLI and CFI represent a good fit when greater than .90, and the value of RMSEA is reasonable when less than .08 (Browne and Cudeck, 1993). In the research model, the covariance lines between WFC and OWFC and between JS and TI were connected. For mediating effect, we applied bootstrapping to confirm the statistical significance of the mediating effect. Bootstrapped standard errors were computed using 1,000 draws. The significance of the mediating effect is interpreted as significant when the bias-corrected 95\% confidence intervals do not include zero.

\section{Results}

In this section, in addition to providing the descriptive statistics and correlations, we provide the results of the SEM analysis.

\section{Descriptive Statistics and Correlations}

Table 2 shows the means, standard deviations, AVEs, and correlations. All correlation coefficients were significant, in part because of the large sample size. With only two exceptions, the correlations were minimal. As expected, the correlation coefficients among FSSB, OWFC, and JS were positively related, while the correlation coefficients associated with WFC and TI were negatively related.

[Place Table 2 about here]

\section{Structural Equation Model Analysis}

We assessed the fitness of a measurement model, the research model (partial mediation model) and nested mediation model (full mediation model). The three models met the recommended criteria (i.e., RMSEA < .05; TLI > .90; and CFI $>$.90). The results showed that the data adequately fit the measurement model $(\chi 2(109)=198.467$, RMSEA $=$ .035 , TLI $=.984$, and CFI $=.987))$. The partial mediation model $(\chi 2(158)=407.245$, RMSEA $=.049, \mathrm{TLI}=.954$, and 
$\mathrm{CFI}=.965)$ was better than the full mediation model $(\chi 2(160)=424.857$, RMSEA $=.050$, TLI $=.952$, and CFI $=$ .962). As the two models are a nested relationship with each other, we also compared the models through a chi-square difference test. The partial mediation model has two degrees of freedom less than the full mediation model, and the chi-square difference exceeds $\chi_{D}^{2}(2)=6.00$. Partial mediation was the case because the direct effects were significant and the path was reduced in absolute size but is still different from zero when the mediator is introduced. Thus, the partial mediation model was used for further analysis.

The results of the structural equation model analysis are shown in Table 3 and Figure 1 . To be specific, FSSB T1 predicted WFC T2 $(\beta=-.299)$, OWFC T3 $(\beta=.277)$, JS T4 $(\beta=.192)$, and TI T4 $(\beta=-.118)$, which supports hypotheses $1,2,3$, and 4, respectively. WFC T2 did not predict JS T4, which does not support hypothesis 5 , while WFC T2 predicted TI T4 $(\beta=.170)$, which supports hypothesis 6 . OWFC T3 also predicted JS T4 $(\beta=.246)$ and TI T4 ( $\beta=-.181$ ), which supports hypotheses 7 and 8 , respectively. In terms of mediating effects, the mediating effect of WFC T2 between FSSB T1 and JS T4 was not significant, which does not support hypothesis 9, while the mediating effect of WFC T2 between FSSB T1 and TI T4 $(\beta=-.051)$ was significant, which supports hypotheses 10 . Finally, the mediating effects of OWFC T3 between FSSB T1 and JS T4 $(\beta=.068)$ and between FSSB T1 and TI T4 $(\beta=-$ .150) were significant, which supports hypotheses 11 and 12 , respectively. The bootstrapping results (1,000 resample) also supports the statistical significance of the three mediating effects because the $95 \%$ confidence interval did not include zero.

[Place Table 3 about here]

[Place Figure 1 about here]

\section{Discussion}

This study examined the structural relationships among FSSBs, WFC, organizational work-family climate, job satisfaction, and turnover intentions. We used a longitudinal mediation model with four different time points to examine the effects of FSSBs over a period of 18 months. The advantages of longitudinal methods are that we can establish a sequence of events and measure changes over time. One-time FSSBs may not quickly change employees' perceptions about their work-family life and the organization; therefore, we provided unique insight that might not be possible with other forms of research.

From a practical significance perspective, none of the relationships among variables were very strong even thought the statistical test results were significant. Supervisor family-supportive behaviors did promote, but minimally, a reduction in an employee's WFC and a positive organizational work-family climate. Employees' high work-to-family conflict had a minimal association with their high turnover intentions. The organizational work-family climate minimally promoted employees' job satisfaction and reduced their turnover intentions. We also found that work-tofamily conflict minimally mediated the relationship between family-supportive supervisor behaviors and turnover intentions, but not between family-supportive supervisor behaviors and job satisfaction. We also found that a perceived organizational work-family climate had a minimally positive relationship with job-related outcomes, with both higher job satisfaction and lower turnover intentions. These findings support earlier findings that FSSBs are positively, though minimally, related to job satisfaction (Hammer et al., 2009; Hammer et al., 2011) and family-supportive organizational cultures (Allen, 2001; Thompson et al., 1999) and are negatively, though minimally, related to WFC and turnover intentions (Hammer et al., 2009; Thompson et al., 1999). The only insignificant direct relationship was between work-family conflict and job satisfaction. According to Hassan (2014), job stress of IT employees was found to be the critical factor that reduced job satisfaction, therefore, it can be interpreted that job stress factors should be taken into consideration when thinking of job satisfaction.

From a theoretical standpoint, we have addressed the importance of considering an organizational climate when explaining social exchange theory, LMX perspectives, or role theory. These theories argue the importance of individual relationships between employees and managers, but we found that linking those relationships to an organizational work-family climate have very little impact. Creating a positive and work-family oriented organizational culture may encourage managers actively to practice FSSBs and use work-family policies (Beauregard and Henry, 2009; Hammer et al., 2009; Major et al., 2008; Poelmans and Beham, 2008), but that may have very little impact on the outcome measures used in this study. 
This is an author-produced, peer-reviewed version of this article. The final, definitive version of this document can be found online at European Journal of Training and Development, published by Emerald Group Publishing, Ltd. Copyright restrictions may apply. doi: 10.1108/EJTD12-2019-0195

In addition, a perceived organizational work-family climate minimally mediated the relationship between FSSB and job-related outcomes, such as job satisfaction/turnover intentions. Not many stuides have included organizational factor level variables, such as a perceived organizational work-family climate or organizational culture, because those variables are difficult to measure, but our study found that their inclusion made little difference in outcomes. As with our results, a recent study (Rofcanin et al., 2017) suggested further research on family-supportive organizational culture because family-supportive organizational perceptions had no relationship with any of the performance or attitude outcomes. The main difference between their research and ours is that the comparison study used a familysupportive organizational culture scale developed by Thompson et al. (1999), whereas we used the Work Climate for Making Family Sacrifices Scale developed by Kossek et al. (2001). Interestingly, these two instruments provided virtually the same results.

Even if there are some implications for theoretical perspective, we may not conclude that there is a practical implication based on our findings. The results of our study imply, minimally, that a supervisor's family-friendly support and care can contribute to improving employees' work-life balance and shape a postitive organizational family supportive climate. However, due to the small variance among relationships, practically, we may have to find other contributing and significant factors that can reduce work-family conflict, create a family-supportive climate, and enhance job-related outcomes. For example, applying system level approaches (e.g., changing reward or evaluation systems, implementing family-oriented policies), in addition to the supervisor's role may lead more positive outcomes. Our study has practical implications by noting that relying on only individual managers' roles or training managers to be family-supportive may not be enough to improve family-oriented organizational culture, work-life balance, and job-related outcomes. Though some scholars have found the positive effects of family friendly policies (e.g., on-site childcare, information services, voluntary compressed workweek, part-time work) on work-fmaily conflict and burnout (Mansour and Tremblay, 2018), organizations should be careful when offering these policies because employees' actual needs and work and life situations are different (Fiksenbaum, 2014). Therefore, this study provides some caution for HRD practitioenrs or HR managers when implementing family-supportive policies or environment.

\section{Limitations and Future Research Suggestions}

The research had some limitations. First, the generalizability of the results are limited because the study used a sample of only two IT companies, though the data were collected from 26 work locations. Second, a self-report instrument was used, which may be subject to respondent bias. In addition, our study focused on data from an existing survey that is also ten years old. However, using this data set is meaningful as these data can be a starting point when comparing it to today's data to see differences, as well as to identify what parts were improved. To expand our study, we recommend several qualitative methods: (a) observe supervisors' FSSB on the job and document specific behaviors that could qualify as FSSBs, (b) interview employees about their supervisors' capacity for exhibiting FSSBs or antiFSSBs, and (c) conduct a focus group interview with supervisors and employees to share their thoughts about FSSBs and its impact on job-related outcomes, WFC, and organizational climates.

The results of our model might be different across different industries. We suggest that using a variable of employees' working hours and how it affects the model might be interesting. Also, the results of our model might be different depending on national context (Las Heras et al., 2015; Qing and Zhou, 2017). For example, most Asian countries tend to have a higher gender gap in salary, and men do the least household chores among the OECD countries (Miller, 2016; OECD, 2014). As a result, women may be reluctant to get married or have children, resulting in a decrease in the labor force and a low birth rate (Raymo et al., 2015). Therefore, researchers need to conduct further cross-national comparisons between men and women (e.g., Ruppanner and Huffman, 2014) on how national context affects the perceptions of FSSBs on job-related outcomes through WFC and family friendly organizational climate.

Finally, future studies should consider a multilevel analysis. In this study, we could not focus on the nested relationship between leader and members because of utilizing secondary data. If there is a sufficient number of leaders and the data of the team members matching the leaders, a multilevel analysis measuring the leaders' FSSB directly can be applied. Similarly, if data from a sufficient number of organizations can be collected, a multi-level analysis will be possible. 


\section{Conclusion}

In this study, we have examined the perceptions of IT employees on a supervisor's family supportive behaviors and how those positive behaviors impact individual work-family conflict and work climate, which, in turn, improve job satisfaction and decrease intentions to quit the job. In spirt of this expectation, however, we found that enhancing support for work-family conflict and changing the workplace culture in the IT industry may contribute very little to the attraction, retention, and satisfaction of employees. We found that a supervisor's family-supportive behaviors do little to create a family-supportive climate within an organization and contribute to mediating the WFC in a household outside an organization. We hope that this study will stimulate future research to advance the theoretical and practical understanding of family-supportive supervisor behaviors to help determine why we found that it had so little impact on both work-life balance and family-friendly organizational climate to increase employees' satisfaction to continue to work.

\section{References}

Allen, T. D. (2001), "Family-supportive work environments: The role of organizational perceptions”, Journal of Vocational Behavior, Vol. 58 No. 3, pp. 414-435, available at: http://doi:10.1006/jvbe.2000.1774

Allen, T. D., Herst, D. E., Bruck, C. S., and Sutton, M. (2000),” Consequences associated with work-to-family conflict: A review and agenda for future research", Journal of Occupational Health Psychology, Vol. 5, No. 2, pp. 278-308 available at: http://doi:10.1037/1076-8998.5.2.278

Anderson, S. E., Coffey, B. S., and Byerly, R. T. (2002), "Formal organizational initiatives and informal workplace practices: Links to work-family conflict and job-related outcomes”, Journal of Management, Vol. 28, No. 6, pp. 787-810, available at: http://doi:10.1177/014920630202800605

Bagger, J., and Li, A. (2014), "How does supervisory family support influence employees' attitudes and behaviors? A social exchange perspective”, Journal of Management, Vol. 40, No. 4, pp. 1123-1150.

Beauregard, T. A., and Henry, L. C. (2009), "Making the link between work-life balance practices and organizational performance”, Human Resource Management Review, Vol. 19, No. 1, pp.9-22 available at: http://doi:10.1016/j.hrmr.2008.09.001

Bolino, M. C., and Turnley, W. H. (2005), "The personal costs of citizenship behavior: the relationship between individual initiative and role overload, job stress, and work-family conflict”, Journal of Applied Psychology, Vol. 90, No. 4, pp. 740-748, available at: http://doi:10.1037/0021-9010.90.4.740

Borges, R. (2013), “Tacit knowledge sharing between IT workers”, Management Research Review, Vol. 36, No. 1, pp. 89-10, available at: http://dx.doi.org/10.1108/01409171311284602

Boroff, K. E., and Lewin, D. (1997), "Loyalty, voice, and intent to exit a union firm: A conceptual and empirical analysis”, Industrial and Labor Relations Review, Vol. 51, No. 1, pp. 50-63, available at: http://doi:10.1177/001979399705100104

Brough, P., O'Driscoll, M. P., and Kalliath, T. J. (2005), "The ability of 'family friendly'organizational resources to predict work-family conflict and job and family satisfaction”, Stress and Health, Vol. 21, No. 4, pp. 223234, available at:http://doi:10.1002/smi.1059

Browne, M. W., and Cudeck, R. (1993), “Alternative ways of assessing model fit”, in K. A. Bollen and J. S. Long (Eds.), Testing structural equation model, Sage, Newbury Park, CA, (pp. 136-162).

Butts, M. M., Casper, W. J., and Yang, T. S. (2013); "How important are work-family support policies? A metaanalytic investigation of their effects on employee outcomes”, Journal of Applied Psychology, Vol. 98, No. 1, pp. 1-25, available at: http://doi:10.1037/a0030389

Byrne, B. M., Shavelson, R. J., and Muthén, B. (1989); “Testing for the equivalence of factor covariance and mean structures: The issue of partial measurement invariance”, Psychological Bulletin, Vol. 105, No. 3, pp. 456466, available at: http://doi:10.1037/0033-2909.105.3.456

Cammann, C., Fichman, M., Jenkins, G. D., and Klesh, J. (1983). "Michigan Organizational Assessment Questionnaire”, in S. E. Seashore, E. E. Lawler, P. H. Mirvis, and C. Cammann (Eds.), Assessing organizational change: A guide to methods, measures, and practices, Wiley-Interscience, New York, NY, pp. 71-138.

Chandra, V. (2012), “Work-life balance: Eastern and western perspectives”, The International Journal of Human Resource Management, Vol. 23, No. 5, pp. 1040-1056, available at: http:// doi: $10.1080 / 09585192.2012 .651339$ 
This is an author-produced, peer-reviewed version of this article. The final, definitive version of this document can be found online at European Journal of Training and Development, published by Emerald Group Publishing, Ltd. Copyright restrictions may apply. doi: 10.1108/EJTD12-2019-0195

Crain, T. L., Hammer, L. B., Bodner, T., Kossek, E. E., Moen, P., Lilienthal, R., and Buxton, O. M. (2014), “Workfamily conflict, family-supportive supervisor behaviors (FSSB), and sleep outcomes”, Journal of Occupational Health Psychology, Vol.19, No. 2, p. 155.

Groysberg, B., and Abrahams, R. (2014), “Manage your work, manage your life”, Harvard Business Review, Vol. 92, No. 3, pp. 58-66.

Fiksenbaum, L. M. (2014), "Supportive work-family environments: implications for work-family conflict and wellbeing”, International Journal of Human Resource Management, Vol. 25, No. 5, pp. 653-672, available at: http://doi:10.1080/09585192.2013.796314

Frone, M. R., Russell, M., and Cooper, M. L. (1992), “Antecedents and outcomes of work-family conflict: Testing a model of the work-family interface”, Journal of Applied Psychology, Vol. 77, No. 1, pp. 65-78, available at: http://doi:10.1037/0021-9010.77.1.65

Greenhaus, J. H., and Beutell, N. J. (1985), "Sources of conflict between work and family roles”, Academy of Management Review, Vol. 10, No. 1, pp. 76-88, available at: https://doi.org/10.2307/258214

Greenhaus, J. H., Ziegert, J. C., and Allen, T. D. (2012), "When family-supportive supervision matters: Relations between multiple sources of support and work-family balance”, Journal of Vocational Behavior, Vol. 80, No. 2, pp. 266-275, available at: http://doi:10.1016/j.jvb.2011.10.008

Hammer, L. B., Ernst Kossek, E., Bodner, T., and Crain, T. (2013), "Measurement development and validation of the Family Supportive Supervisor Behavior Short-Form (FSSB-SF)”, Journal of Occupational Health Psychology, Vol. 18, No. 3, pp. 285-296, available at: http://doi:10.1037/a0032612

Hammer, L. B., Kossek, E. E., Anger, W. K., Bodner, T., and Zimmerman, K. L. (2011), “Clarifying work-family intervention processes: The roles of work-family conflict and family-supportive supervisor behaviors", Journal of Applied Psychology, Vol. 96, No. 1, 134-150, available at: http://doi:10.1037/a0020927

Hammer, L., Kossek, E., Yragui, N., Bodner, T., and Hansen, G. (2009), "Development and validation of a multidimensional scale of family supportive supervisor behaviors (FSSB)”, Journal of Management, Vol. 35, No. 4, pp. 837-856, available at: http://doi:10.1177/0149206308328510

Hassan, R. (2014), "Factors influencing turnover intention among technical employees in information technology organization: A case of XYZ (M) SDN. BHD”, International Journal of Arts and Commerce, Vol. 3, No. 9, pp. 120-137.

Hong, S., Malik, M. L., and Lee, M. K. (2003), “Testing configural, metric, scalar, and latent mean invariance across genders in sociotropy and autonomy using a non-Western sample”, Educational and Psychological Measurement, Vol. 63, No. 4, pp. 636-654, available at: http://doi:10.1177/0013164403251332

Kaminski, J. A. M., and Reilly, A. H. (2004), “Career development of women in information technology”. SAM Advanced Management Journal, Vol. 69, No. 4, pp. 20-30.

Kossek, E. E., Colquitt, J. A., and Noe, R. A. (2001), "Caregiving decision, well-being, and performance: The effects of place and provider as a function of dependent type and work-family climates”, Academy of Management Journal, Vol. 44, No. 1, pp. 29-44,available at: http://doi:10.2307/3069335

Kossek, E. E., Pichler, S., Bodner, T., and Hammer, L. B. (2011), "Workplace social support and work-family conflict: A meta-analysis clarifying the influence of general and work-family-specific supervisor and organizational support”, Personnel Psychology, Vol. 64, No. 2 pp. 289-313, available at: http://doi:10.1111/j.1744-6570.2011.01211.x

Las Heras, M., Trefalt, S., and Escribano, P. I. (2015), "How national context moderates the impact of familysupportive supervisory behavior on job performance and turnover intentions”, Management Research: The Journal of the Iberoamerican Academy of Management, Vol. 13, No. 1, pp. 55-82, available at http://doi:10.1108/MRJIAM-06-2014-0556

Major, D. A., Fletcher, T. D., Davis, D. D., and Germano, L. M. (2008), "The influence of work-family culture and workplace relationships on work interference with family: a multilevel model”, Journal of Organizational Behavior, Vol. 29, No. 7, pp. 881-897 available at: http://doi:10.1002/job.502

Mansour, S., and Tremblay, D. G. (2018). "Work-family conflict/family-work conflict, job stress, burnout and intention to leave in the hotel industry in Quebec (Canada): moderating role of need for family friendly practices as resource passageways", The International Journal of Human Resource Management, Vol. 29, No. 16, pp. 2399-2430, available at: https://doi.org/10.1080/09585192.2016.1239216

Martinengo, G., Jacob, J. I., and Hill, E. J. (2010), “Gender and the work-family interface: Exploring differences across the family life course”, Journal of Family Issues, Vol. 31, No. 10, pp. 1363-1390, available at: http://doi:10.1177/0192513X10361709 
This is an author-produced, peer-reviewed version of this article. The final, definitive version of this document can be found online at European Journal of Training and Development, published by Emerald Group Publishing, Ltd. Copyright restrictions may apply. doi: 10.1108/EJTD12-2019-0195

Mesmer-Magnus, J. R., and Viswesvaran, C. (2005), “Convergence between measures of work-to-family and family-to-work conflict: A meta-analytic examination”, Journal of Vocational Behavior, Vol. 67, No. 2, pp. 215-232, available at: http://doi:10.1016/j.jvb.2004.05.004

Michel, J. S., Mitchelson, J. K., Pichler, S., and Cullen, K. L. (2010), “Clarifying relationships among work and family social support, stressors, and work-family conflict”, Journal of Vocational Behavior, Vol. 76, No. 1, pp. 91-104, available at: https://doi.org/10.1016/j.jvb.2009.05.007

Miller, C. C. (2016), “How society pays when women’s work is unpaid”, The New York Times, 21 February, available at: http://www.nytimes.com/2016/02/23/upshot/how-society-pays-when-womens-work-isunpaid.html

Munn, S. L. (2013), "Unveiling the work-life system: the influence of work-life balance on meaningful work", Advances in Developing Human Resources, Vol. 15, No. 4, pp. 401-417, available at: https://doi.org/10.1177/1523422313498567

Netemeyer, R. G., Boles, J. S., and McMurrian, R. (1996), "Development and validation of work-family conflict and family-work conflict scales”, Journal of Applied Psychology, Vol. 81, No. 4, pp. 400-410, available at: http://doi:10.1037/0021-9010.81.4.400

O’Brien, K. M., Ganginis Del Pino, H. V., Yoo, S.-K., Cinamon, R. G., and Han, Y.J. (2014), "Work, family, support, and depression: Employed mothers in Israeli, Korea, and the United States”, Journal of Counseling Psychology, Vol. 61, No. 3, pp. 461-472, available at: http://doi: 10.1037/a0036339

Odle-Dusseau, H. N., Britt, T. W., and Greene-Shortridge, T. M. (2012), “Organizational work-family resources as predictors of job performance and attitudes: The process of work-family conflict and enrichment”. Journal of Occupational Health Psychology, Vol. 17, No. 1, pp. 28-40, available at http://doi:10.1037/a0026428

OECD (2014), OECD Better Life Index 2015, available at: http://www.oecdbetterlifeindex.org/topics/work-lifebalance/

OECD (2014), OECD Factbook 2014, available at: http://www.oecd-ilibrary.org/economics/oecd-factbook2014/total-fertility-rates_factbook-2014-table8-en

Offer, S. (2014), "The costs of thinking about work and family: Mental labor, work-family spillover, and gender inequality among parents in dual-earner families”, Sociological Forum, Vol. 29, No. 4, pp. 916-936, available at: http://doi:10.1111/socf.12126

O’Neill, J. W., Harrison, M. M., Cleveland, J., Almeida, D., Stawski, R., and Crouter, A. C. (2009), "Work-family climate, organizational commitment, and turnover: Multilevel contagion effects of leaders", Journal of Vocational Behavior, Vol. 74, No. 1, pp. 18-29, available at: http://doi:10.1016/j.jvb.2008.10.004

O’Neil, D. A., Hopkins, M. M., and Bilimoria, D. (2008), "Women's careers at the start of the $21^{\text {st }}$ century: Patterns and paradoxes”, Journal of Business Ethics, Vol. 80, No. 4, pp. 727-743, available at: http://doi: 10.1007/s10551-007-9465-6

Özbilgin, M. F., Beauregard, T. A., Tatli, A., and Bell, M. P. (2011), "Work-life, diversity and intersetionality: A critical review and research agenda”, International Journal of Management Review, Vol. 13, No. 2, pp. 177-198, available at: http://doi:10.1111/j.1468-2370.2010.00291.x

Pitt-Catsouphes, M., Matz-Costa, C., and MacDermid, S. M. (2007), "HRD responses to work-family stressors", Advances in Developing Human Resources, Vol. 9, No. 4, pp. 527-543, available at: https://doi.org/10.1177/1523422307305491

Poelmans, S., and Beham, B. (2008), "The moment of truth: Conceptualizing managerial work-life policy allowance decisions”, Journal of Occupational and Organizational Psychology, Vol. 81, No. 3, pp. 393-410, available at: http://doi:10.1348/096317908X314865

Qing, G., and Zhou, E. (2017), "Bidirectional work-family enrichment mediates the relationship between familysupportive supervisor behaviors and work engagement”, Social Behavior and Personality: an International Journal, Vol. 45, No. 2, pp. 299-308.

Raymo, J. M., Park, H., Xie, Y., and Yeung, W. J. (2015), "Marriage and family in East

Asia: Continuity and change”, Annual Review of Sociology, Vol. 41, No. 1, pp. 471-492, available at: http://doi:10.1146/annurev-soc-073014-112428

Rofcanin, Y., Las Heras, M., and Bakker, A. B. (2017), "Family supportive supervisor behaviors and organizational culture: Effects on work engagement and performance”, Journal of occupational health psychology, Vol. 22, No. 2, p. 207.

Ruppanner, L., and Huffman, M. L. (2014), "Blurred boundaries: Gender and work-family interference in crossnational context”, Work and Occupations, Vol. 41, No. 2, pp. 210-236, vailable at: http://doi:10.1177/0730888413500679 
This is an author-produced, peer-reviewed version of this article. The final, definitive version of this document can be found online at European Journal of Training and Development, published by Emerald Group Publishing, Ltd. Copyright restrictions may apply. doi: 10.1108/EJTD12-2019-0195

Thompson, C. A., Beauvis, L. L., and Lyness, K. S. (1999), "When work-family benefits are not enough: The influence of work-family culture on benefit utilization, organizational attachment, and work-family conflict”. Journal of Vocational Behavior, Vol. 54, pp. 392-415, available at: http://doi:10.1006/jvbe.1998.1681

Tummers, L. G., \& Bronkhorst, B. A. (2014), “The impact of leader-member exchange (LMX) on work-family interference and work-family facilitation”. Personnel Review, Vol. 43, No. 4, pp. 573-591, available at: https://doi.org/10.1108/PR-05-2013-0080

Valcour, M. (2007), "Work-based resources as moderators of the relationship between work hours and satisfaction with work-family balance”, Journal of Applied Psychology, Vol. 92, No. 6, pp. 1512-1523, available at: http://doi:10.1037/0021-9010.92.6.1512

Way, S. F. (2015), "Midcareer women leaving information technology: An examination of the phenomenon (Doctoral dissertation)", available at: http://scholarworks.waldenu.edu/dissertations/307/

West, S. G, Finch, J. F., and Curran, P. J. (1995), "Structural equation models with nonnormal variables: Problems and remedies”, in R. H. Hoyle (Ed.), Structural equation modeling: Concepts, issues, and applications, Sage, Thousand Oaks, CA, pp. 56-75. 